\title{
Agglutination-separation reactions of red blood cells sensitized with Newcastle disease virus: quantities, agglutination characteristics, and serology of altered virus and $\mathrm{HN}$ spikes released following neuraminidase reactivation
}

\author{
I.L. GRAVES
}

Department of Molecular Microbiology and Immunology, School of Hygiene and Public Health, The Johns Hopkins University, 615 North Wolfe Street, Baltimore, Maryland 21205 USA

(Received 22 May 2000; accepted 26 April 2001)

\begin{abstract}
Red blood cells (RBC) become sensitized following the elution of strain 575 Newcastle disease virus (NDV). The neuraminidase (NA) in the haemagglutinin (HA)-sialic acid configuration is inactive. The HA on sensitized RBC agglutinates normal RBC. The sialic acid on normal RBC initiated reactivation of the NA-a newly described function. Then normal-sensitized RBC agglomerates separated at $37^{\circ} \mathrm{C}$ in the irreversible agglutination-separation (AS) reactions. With separation the AS products, HN spikes (150-200 kDa) and altered NDV, which contain fewer HN spikes than intact allantoic NDV, were removed from the sensitized RBC and the NDV membrane. Extraction of HN spikes from the membrane required more sialic acid than the removal of AS products from RBC. Thus 2 reactions were delineated for the orderly removal. Amounts of each released AS product suggest the source of the HN spikes. AS reactions and ether treatment of NDV increased the HA titres up to 19.2 fold. HA-sialic acid configurations were estimated by the amounts of normal RBC agglutinated by sensitized RBC and also by agglutination with fetuin. Elution of B1 vaccine, HN spikes from ether-treated NDV as well as AS products separated on sephadex resulted in incompletely sensitized RBC; fewer configurations were titrated with normal RBC; all failed to respond to anti-NA antibody. In contrast, sensitized RBC or suspensions of $575 \mathrm{NDV}$, but not the B1 vaccine strain, responded to both anti-NA and anti-HA antibody. Sensitization, slow elution, and responding to anti-NA antibody, which was accompanied by fluorescent foci on sensitized RBC, required intact NDV and the infrequent HA-sialic acid configuration. The NA was inactive for the HA-sialic acid configuration but cleaved fetuin, indicating substrate specificity. An inactive NA would allow time for fusion and NDV penetration rather than elution by an active NA early in NDV infection.
\end{abstract}

Newcastle disease virus / agglutination-separation reactions of sensitized RBC / neuraminidase reactivation / new sialic acid function / HN serologic configurations 
Résumé - Réactions d'agglutination-séparation d'hématies sensibilisées avec le virus de la maladie de Newcastle : caractéristiques de l'agglutination et sérologie des produits de réaction et nouvelle fonction de l'acide sialique. Les hématies se trouvent sensibilisées après élution de la souche 575 du virus de la maladie de Newcastle (NDV). La neuraminidase (NA) est inactive dans la configuration hémagglutinine (HA)-acide sialique. La HA des hématies sensibilisées agglutine les hématies normales. L'acide sialique des hématies normales entraîne la réactivation de la NA (fonction nouvellement décrite). Alors les agglomérats d'hématies normales et d'hématies sensibilisées sont séparées à $37^{\circ} \mathrm{C}$ dans des réactions irréversibles d'agglutination-séparation (AS). Avec la séparation les produits de l'AS, c'est-à-dire les pointes de HN (150-200 kDa) et le NDV altéré (qui contient moins de pointes de HN que le NDV intact) étaient éliminés des hématies sensibilisées et de la membrane du NDV. L'extraction des pointes de HN à partir de la membrane a nécessité plus d'acide sialique que l'élimination des produits AS à partir des hématies. Les quantités de chaque produit de l'AS relargué indiquent la source des pointes de HN. Les réactions de l'AS et le traitement du NDV à l'éther ont augmenté les titres jusqu'à 19,2 fois. Les configurations HA-acide sialique ont été estimées par les quantités d'hématies normales agglutinées par les hématies sensibilisées et aussi par agglutination avec la fétuine. L'élution du vaccin B1, des pointes de HN à partir du NDV traité à l'éther ainsi que des produits AS séparés sur Sephadex a produit des hématies incomplètement sensibilisées. Moins de configurations ont été titrées avec des hématies normales; elles ne répondaient pas à l'anticorps anti-NA. À l'inverse, des hématies sensibilisées ou des suspensions de NDV 575 (mais pas du vaccin B1) ont répondu à la fois à l'anticorps anti-NA et à l'anticorps anti-HA. Sensibilisation, élution lente et réponse à l'anticorps anti-NA, qui étaient accompagnés de foyers fluorescents sur les hématies sensibilisées, ont nécessité du NDV intact et la configuration rare HAacide sialique. La NA était inactive pour la configuration HA-acide sialique mais clivait la fétuine indiquant la spécificité du substrat. Une NA inactive permettrait d'augmenter le temps nécessaire pour la fusion et la pénétration du NDV plutôt que son élution par une NA active très tôt lors d'une infection par le NDV.

virus de la maladie de Newcastle / réactions d'agglutination-séparation des hématies sensibilisées / pointes de HN / nouvelle fonction de l'acide sialique / configurations sérologiques de la HN

\section{INTRODUCTION}

Red blood cells (RBC) sensitized following the elution of 575 Newcastle disease virus (NDV), retain haemagglutinins (HA) bound to the $\mathrm{N}$-acetylneuraminic acid (sialic acid) receptors. The neuraminidase (NA) (sialidase) in the HA-sialic acid configuration is inactive, which results in $\mathrm{RBC}$ sensitization. Sensitized and normal RBC form agglomerates. The agglomerates separate releasing altered NDV and HA-NA glycoprotein spikes (HN spikes), the 2 products of the agglutination-separation (AS) reactions [26].

Importantly, only the NA has been found in cHN crystals [48] from the Kansas strain [11]. Still, regarding HA and NA activities in suspensions of strain 575, mild heat eliminated the NA antibody attachment determinants, then the NA, and lastly, the HA was inactivated [24]. Also, the antibody prevalences for the HA and NA have been estimated with acceptable accuracy in 2 avian populations [22,25]. And as presented here, the inhibiting effects of antibodies show separation of the HA and NA on sensitized RBC under defined, but not all, conditions.

The purposes of this report are: 1) To describe the effects of graded concentrations of the sialic acid in the 2 reactions which remove AS products from sensitized RBC and the NDV membrane; 2) To describe the anti-NA and anti-HA antibody reactions of sensitized RBC; 3 ) To describe the agglutination and serologic limitations of the AS products, $\mathrm{B} 1$ vaccine, and $\mathrm{HN}$ spikes from ether-treated NDV; 4) To quantify the configurations which contain the inactive NA by agglutination with normal RBC and with fetuin; 5) To describe the specificity of the NA substrate; 6) To further interpret the initial sensitization experiments 
[2, 5, 6, 8, 29]; 7) To suggest a molecular mechanism for the inactive NA; functions of an active NA have been proposed [14, 26, $36,48]$.

\section{MATERIALS AND METHODS}

\subsection{NDV strains 575 and B1, antisera, $\mathrm{RBC}$ and sensitization of RBC}

Strain 575 (PMV-1/Mute swan/Maryland/575/1977) and its biological purification are described elsewhere [22, 24-26]. Considering the failure to completely sensitize [26] and the known differences [4, 40, $43,45]$, the B1 vaccine was compared with strain 575. The 16th passage in eggs [4] was obtained from the late F.B. Bang, The Johns Hopkins University, Baltimore, MD, USA. The anti-serum, also from F.B. Bang, was from rabbits 33 and 98 , raised with the $B$ (Beaudette) strain [29], and drawn 17 days post immunization. Another immune serum, raised in chickens with the Roakin strain, was from the Center for Disease Control (CDC), Atlanta, GA, USA. Adsorption with chicken RBC was necessary before use. RBC from two leghorn chickens, selected by trial and error testing, were washed and suspended at $0.3 \%$ concentration in phosphate $(0.05 \mathrm{M})$ buffered ( $\mathrm{pH} 7.2-7.4) \mathrm{NaCl}$ (0.14M) (PBS) containing $0.1 \% \mathrm{NaN}_{3}$. Certain RBC do not sensitize [4] or agglutinate [5] to the same degree as RBC from appropriate donor birds and are also unsuitable for anti-NA antibody tests with NDV [22, $24,25]$ and influenza viruses [3, 23]. Such RBC may have reduced concentrations of the HA-sialic acid configurations estimated in the titrations below.

The HA units required for agglutination also sensitize the RBC [5, 6]. Approximately $1200 \mathrm{HA}$ units of $575 \mathrm{NDV}$ in allantoic fluid were mixed with $0.1 \mathrm{~mL}$ of packed $\mathrm{RBC}$ at $25{ }^{\circ} \mathrm{C}$. The RBC were incubated at $37{ }^{\circ} \mathrm{C}$ for 2 to $3 \mathrm{~h}$. Agglutination was no longer visible. The resultant sensitized RBC were washed 3 times with approximately 50 vol- umes of PBS and used at a $0.3 \%$ concentration. Haemolysis occurred during sensitization as noted by others [6-8]. The probable cause is the F glycoprotein $[30,36]$. The haemoglobin was removed by centrifugation; thus the subsequent analysis was unaffected.

\subsection{Stability of sensitized RBC during storage and heat inactivation of the NA and HA}

Sensitized RBC have been stored in PBS at $5{ }^{\circ} \mathrm{C}$ for 66 days without losing HA or NA activities as determined in the AS serologic reactions herein described. Loss of haemoglobin occurs. However, the sensitized RBC ghosts retain the activities. Heat at $51{ }^{\circ} \mathrm{C}$ to $60{ }^{\circ} \mathrm{C}$ does not cleave the HAsialic acid bond(s) [12]. Rather, the NA and HA activities are sequentially inactivated by proposed conformational changes [26, 47].

\subsection{Agglutination-separation reactions and HA-sialic acid configuration quantification}

One volume $(0.025 \mathrm{~mL})$ of sensitized RBC was dispensed into each of 7 wells of a microtitre plate. One to 7 volumes of $0.3 \%$ normal RBC were added; the volumes were equalized with PBS. The tests were incubated at $37{ }^{\circ} \mathrm{C}$ in a humidified atmosphere until separation of the agglomerates ceased. As with the elution-inhibition (EI) reaction or in heat inactivation studies, the time was unspecified [24, 26]. End points were usually reached within $16 \mathrm{~h}$.

The HA on sensitized RBC are titrated with normal RBC [26]. The HA so estimated is associated with the HA-sialic acid configuration which contains the inactive NA. Thus the titration estimates the HA as well as the configuration. The frequency is expressed in volumes of normal RBC. 


\subsection{Non-limited and limited sialic acid concentrations in the AS reactions; tests for end points and change in the ratios of $\mathrm{AS}$ products}

Following mild heating of sensitized $\mathrm{RBC}$, the titrations with normal RBC showed that increased concentrations of $\mathrm{RBC}$, that is sialic acid, were required to release the AS products [26]. Thus the limiting and governing entity is sialic acid; the concentration is expressed in volumes of RBC.

In non-limited sialic acid experiments one volume $(0.3 \mathrm{~mL})$ of sensitized RBC formed agglomerates with 3 volumes of normal RBC. The agglomerates were incubated at $37^{\circ} \mathrm{C}$ for $3 \mathrm{~h}$, at which time the separation was complete. Supernatant fluid was collected, the separated RBC were washed twice in PBS, and HA content of each fluid was estimated by HA titration and expressed in HA units. A third washing did not yield more HA.

To limit the sialic acid concentrations RBC were added sequentially to sensitized RBC. Equal volumes $(0.3 \mathrm{~mL})$ of normal and sensitized RBC formed agglomerates. After incubation, separation, centrifugation and removal of the supernatant fluid, the pellet was suspended in PBS. A second volume of normal RBC was added to the $1 / 1$ preparation. The incubations and the washing were repeated. To test if the end point in the second AS reaction was attained, a third volume of RBC was added. No agglutination was seen, nor were HA units present in the supernatant fluids following incubation. Thus end points were reached with 2 sequential additions of RBC.

Altered NDV was used as a reference to estimate the change in the ratios of the AS products with limited, followed by non-limited sialic acid concentrations in the AS reaction; 2 reactions were delineated. Similar methods have been used in molecular mass estimates from the ratios of Hela cell glycogen particles/latex spheres, also in determining the specific activities of radioactive macromolecules in rates of synthesis measurements [19-21].

\subsection{Ether treatment of NDV and fluorescent antibody staining}

NDV was treated with ether [24, 42] to test if $\mathrm{HN}$ spikes derived from another method would reproduce the reactions of $\mathrm{HN}$ spikes released in the AS reactions. The RBC agglutinated with ether-treated NDV also released varying amounts of haemoglobin which required washing in PBS. The RBC, agglutinated with HN spikes, showed uniform fluorescent antibody staining. No "foci" indicating NDV aggregation were seen [24]. HN spikes from the sensitizing Australia-Victoria (AV) strain also remain on human $\mathrm{RBC}$ [40].

\subsection{Nomenclature for NDV released in the AS reactions, the 4 applications of the term agglutination, agglutination with $\mathrm{RBC}$, and the definition for incompletely sensitized RBC}

The term "altered NDV" is used to denote the NDV on sensitized RBC, which is released in the AS reactions. Altered NDV is distinguished from intact NDV in allantoic fluid and from NDV that elutes from RBC in the sensitization process. The NDV eluted during sensitization will not continue to sensitize $[2,6]$ nor respond to anti-NA antibody (unpublished results). Thus, purification by agglutination, then centrifugation followed by elution from RBC results in a non-uniform population. After separation terms defining the NDV will be needed.

The term agglutination describes the appearance of the RBC after mixing 1) NDV and normal RBC, 2) normal and sensitized $\mathrm{RBC}, 3)$ fetuin and sensitized RBC, and 4) polyclonal antisera and sensitized RBC. 
To quantify the agglutination capacity of RBC sensitized with strain 575 and to compare this capacity with RBC agglutinated with the $\mathrm{B} 1$ vaccine, ether-treated 575 , and the AS products, the HA on the RBC were titrated with normal RBC. The following definition is based on this HA titration. If the HA on RBC from any preparation formed agglomerates with fewer than 6-7 volumes of normal RBC, the RBC in question are incompletely sensitized. This definition is supported by the anti-NA serologic reactions described below.

\subsection{Sephadex chromatography and partial purification}

The void volume measurements and calibration of the $50 \times 1 \mathrm{~cm}$ column with blue dextran as well as the protein and carbohydrate markers have been described [24]. Altered NDV and the HN spikes in the $0.5 \mathrm{~mL}$ fractions from $\mathrm{G}-200$ sephadex were located and quantities estimated by the HA titration. The HN spikes from the AV strain have also been purified on G-200 [40]. Bovine gamma globulin (BGG), 150$160 \mathrm{kDa}$, and avian haemoglobin, $72 \mathrm{kDa}$, if released during the $\mathrm{AS}$ reactions, were located by absorptions at $280 \mathrm{~nm}$.

Partial purification of NDV by centrifugation indicated that tetrameric $\mathrm{HN}$ spikes were not present in allantoic fluid [24]. To test for smaller macromolecules, the allantoic fluid was chromatographed. All HA units were located in the void volumes of G-50 and G-75 sephadex columns.

\subsection{Cleavage of sialic acid from fetuin by the NA on sensitized RBC; agglutination of sensitized $\mathrm{RBC}$ with fetuin and estimates of the HA-sialic acid configurations}

Fetuin (Sigma Chemical Corporation, St. Louis, MO, USA) agglutinates sensitized $\mathrm{RBC}$ and contains a range of $5.9 \%-8.7 \%$ sialic acid, approximately $7 \%$ of which is $\mathrm{N}$-glycolyneuraminic acid. An average of 13.6 sialic acid residues are present in the $48.4 \mathrm{kDa}$ molecule $[16,17]$. Because the shape of fetuin may limit the number of residues involved in the agglutination of sensitized RBC, the weight, rather than the number of residues, would best express the equivalence with the free HA in the HAsialic acid configurations. Further, the equivalence with sialic acid on normal RBC can be estimated.

To estimate cleavage as well as the quantity of fetuin required for partial and complete agglutinations, 1 volume $(0.025 \mathrm{~mL})$ to 5 volumes of sensitized RBC were added to $0.625 \mathrm{mg}$ fetuin contained in $0.05 \mathrm{~mL}$ PBS. The volumes of the tests were equalized with PBS. The tests were incubated for $16 \mathrm{~h}$ at $37{ }^{\circ} \mathrm{C}$. Release of $\mathrm{N}$-acetylneuraminic acid (NANA) was estimated at $549 \mathrm{~nm}$ using standard methods [1] and expressed in optical density (O D) units.

The agglutination of sensitized RBC with the sialic acid in fetuin has some similarity with immobilized fetuin used in chromatography [33]; the results suggested that the NA but not the HA was on the HN spike [11].

\subsection{Tests with NDV suspensions: haemagglutination-inhibition (HI) and elution-inhibition (EI)}

The HI and EI tests used 24 HA units of 575 and B1 strains. The EI tests require a minimum of 16 HA units of strain 575 [22, 24, 25].

\subsubsection{Initial undefined reactions with sensitized RBC: agglutination and pellet formation}

In the agglutination test, sensitized RBC $(0.025 \mathrm{~mL})$ were added to 2 -fold dilutions of antiserum. For convenience, the mixtures were held at $10{ }^{\circ} \mathrm{C}$ for $16 \mathrm{~h}$ although bindings with antibody were found to be rapid 
(unpublished results). The agglutination test has two components: 1) Pellets of sensitized RBC may form at low serum dilutions although this is an inconsistent finding. 2) An agglutination pattern forms at antiserum dilutions above those causing pellet formation [4, 29].

The contribution of the NDV compo$\operatorname{nent}(\mathrm{s})[14,30,36]$ in the agglutination or pellet formation are undefined although the reactions aid in explaining the tests described below.

\subsubsection{Tests with sensitized and normal RBC: agglutination-inhibition (AI) and separation-inhibition (SI) tests}

In the AI test an equal volume (0.025) of $0.3 \%$ normal RBC was mixed with the $\mathrm{RBC}$ in the pellet formation and agglutination reactions described above. The sensitized RBC are used as an NDV suspension in $\mathrm{HI}$ and EI reactions. Thus the AI patterns, analogous to the HI test, were pellets of RBC. No incubation is required, nor was the duration of the AI test set.

After recording the AI titres, the SI tests were incubated at $37{ }^{\circ} \mathrm{C}$ in a humidified atmosphere until the separation of the agglomerates ceased. End points were permanent agglutination patterns. The incubation time was not fixed. Usually the incubation required 16-24 h to attain end points. The SI agglutination patterns are analogous to those of the EI tests [22-25]. Unlike the EI in combination with the HI test [25], the AI and SI assay the inhibition of the HA and NA within 1 system allowing direct comparisons [11].

With protracted incubation the RBC often release haemoglobin resulting in ghosts that were clearly visible with indirect lighting, thus allowing accurate estimates of SI titres. If an end point did not occur at a specific dilution, the next higher dilution showing a partial (+/-), although permanent end point was used to calculate an average of the
2 dilutions in question. Results from duplicate tests were averaged. Although this afforded increased accuracy, the numerically expressed results deviate from the inverse of the $\log 2$ dilution.

\section{RESULTS}

\subsection{Increase in $\mathrm{HA}$ units released in the AS reactions with non-limited sialic acid concentrations}

Following sensitization of RBC with 2688 HA units, the supernatant fluid contained 2496 HA units of eluted NDV. Agglutination with 3 volumes of normal RBC resulted in the wash fluids containing 19,000 HA units. Thus an 8-fold increase in HA units was released when compared with the HA units used to sensitize the RBC. The increase in HA units in 2 other experiments was 8.9- and 16-fold.

\subsection{Increase in HA units following ether-treatment of NDV}

To test if the increase in HA units occurred only in the AS reactions NDV was etherized. The HA titres increased from 48 to $192 \mathrm{HA}$ units per $0.025 \mathrm{~mL}$, hence the increase was 4-fold; in another experiment the increase was 8-fold. The etherized suspensions, used in attempts to sensitize RBC as described below, were not adjusted to compensate for the increase in HA units.

\subsection{Sephadex G-200 chromatography of NDV in allantoic fluid, eluted NDV, and the products released in the AS reactions with non-limited sialic acid concentrations}

To test for HN spikes in allantoic fluid (3550 HA units) as well as in suspensions eluted from RBC during the sensitization (3600 HA units), each was 
chromatographed. The void volume in fractions 19-33, with peak values in fractions 24-27, contained all the HA units. Thus the $\mathrm{HN}$ spikes were not present in allantoic fluid nor released from sensitized RBC or NDV during or after the sensitization process. Allantoic NDV in fractions 25 and 28 were used in the tests described below.

The AS products showing an 8-fold increase in HA units from the $3 / 1$ nor$\mathrm{mal} / \mathrm{sensitized} \mathrm{RBC}$ preparation (thus a nonlimited AS reaction) were chromatographed. The void volume in fractions 25-27 contained altered NDV; the HN spikes were located in fractions 30-37. The ratio of $\mathrm{HN}$ spike/altered NDV was 5.7 $(7760 / 1360=5.7)$.

\subsection{Change in the composition of the AS products with limited, followed by non-limited sialic acid concentrations and the increase in HA units released}

The HA units in the washes, when equal volumes of sensitized and normal RBC reacted (thus a limited sialic acid reaction), were 86,016, 288, and 120; after a second volume of RBC was added, the released HA units in the washes were $23,552,1024$, and 2160. Addition of a third volume of normal $\mathrm{RBC}$ failed to release more AS products.

The HN spike/altered NDV ratio in the limited AS reaction was 0.72 ; this ratio increased to 3 in the non-limited AS reaction. With limited versus non-limited sialic acid concentrations, the altered NDV had the greatest change $(8440 / 400=21.1)$, whereas the change in HN spikes was less $(6060 / 1200=5.1)$ (Fig. 1). Removal of altered NDV was accomplished with less sialic acid than the extraction of HN spikes.

Of the 6144 HA units used in sensitization, 5120 units eluted from the $0.3 \mathrm{~mL}$ of sensitized RBC. The eluted HA units plus the HA units in washes divided by the HA units used in sensitization showed a 19.2fold increase $(118,100 / 6144=19.2)$.

\subsection{Approximation of the molecular mass of the HN spikes released in the $\mathrm{AS}$ reactions}

The BGG peak concentration was located in fractions 37-39, whereas the HN spikes were in fractions 30-34 (Fig. 1). The value for the molecular mass of the HN spike was between $200 \mathrm{kDa}$, the limit of G-200, and $150-160 \mathrm{kDa}$. The avian haemoglobin peak concentration was located in fractions 53-54.

\subsection{Cleavage of sialic acid from fetuin by the NA on agglutinated and non-agglutinated sensitized RBC}

The sensitized RBC were $100 \%$ agglutinated with fetuin at 0.63 and $0.31 \mathrm{mg}$ per $0.025 \mathrm{~mL}$ RBC; approximately $50 \%$ agglutination occurred with $0.21 \mathrm{mg}$, and no agglutination was seen with 0.16 and $0.13 \mathrm{mg}$ fetuin. The NANA in the supernatant fluid from the preparations with $100 \%$ agglutination showed an $\mathrm{O} D$ of 0.12 and 0.09 ; with $50 \%$ as well as with no agglutination the tests showed an O D of 0.11 .

\subsection{Differences in the elution rates of altered NDV, HN spikes and ether-treated 575}

HN spikes in the sephadex fractions eluted rapidly when compared with altered NDV. HA titres of $1 / 64-1 / 128$ declined to $1 / 2+/-1 / 4$ in $30 \mathrm{~min}$ at $25^{\circ} \mathrm{C}$. In contrast, no elution was apparent at $30 \mathrm{~min}$ for altered NDV with similar HA titres. Ether-treated NDV showed an HA titre of 1/128, which declined to $1 / 8$ in $1.5 \mathrm{~h}$, whereas without ether treatment no elution was seen. 


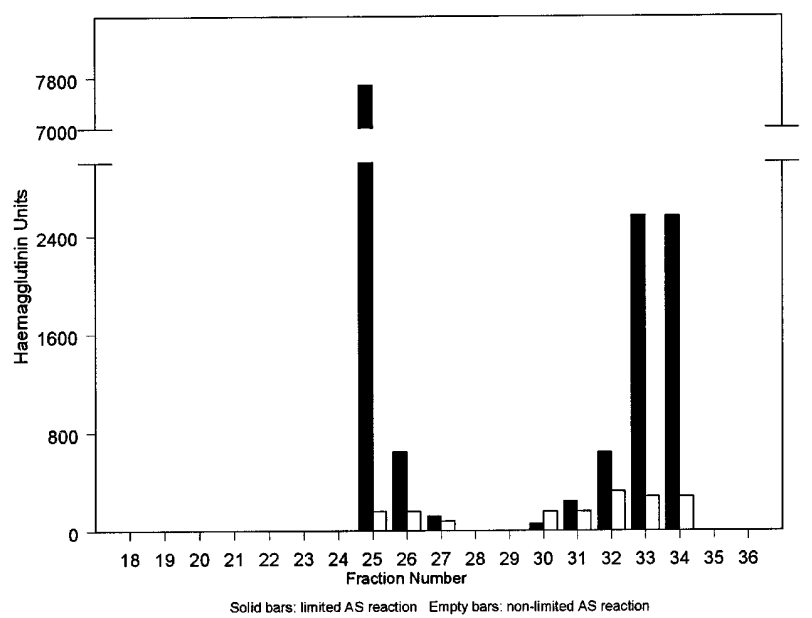

Figure 1. Sephadex G-200 chromatography of altered Newcastle disease virus and HN spikes released in limited and non-limited sialic acid agglutination-separation (AS) reactions. The limited AS reaction contained equal volumes of normal RBC and sensitized RBC. Altered NDV (8440 HA units) and HN spikes (6060 HA units) were released from the sensitized RBC. After the AS products were removed a $2^{\text {nd }}$ volume of normal $\mathrm{RBC}$ was added; the sialic acid concentration was non-limited. Altered NDV (400 HA units) and HN spikes (1200 HA units) were released. Titrations and serology reactions of the altered NDV in fraction 25 and HN spikes in fraction 34 appear in Tables I and II.

\subsection{Incomplete sensitization of $\mathrm{RBC}$ following the elution of the B1 strain, ether-treated NDV, and the AS products evaluated by the titration of the HA on the RBC}

The RBC agglutinated with the B1 strain showed small agglomerates when compared with strain 575, and the elution was rapid. Equal volumes of normal RBC agglutinated the RBC from which the B1 had eluted. Again, small agglomerates formed. Following the incubation and separation of the agglomerates, the HA titre in the fluid was $<1 / 2$. Similar results were obtained in attempts to sensitize RBC with $\mathrm{HN}$ spikes from ether-treated NDV as well as the HN spikes from sephadex fraction 34 and the altered NDV in fraction 25 (Tab. I). With incompletely sensitized RBC, the concentrations of the released products may have been below the level of detection in the HA assay. The released AS products were found only in preparations containing RBC sensitized with allantoic NDV.

\subsection{Antibody reactions with sensitized and incompletely sensitized RBC and with suspensions of NDV}

The HA responded to antibody in both the AI and HI tests. The NA responded only in the SI test if the RBC were sensitized with control NDV from fraction 25 and in the EI tests with suspensions of strain 575 . The B1 strain responded only in HI tests. Neither SI nor EI antibodies were detected with RBC incompletely sensitized with altered NDV and HN spikes together or after separation on sephadex. The NA was functional as shown by the separation of the agglomerates in the AS test (Tab. II). 
Table I. Titration of haemagglutinins (HA) and HA-sialic acid configurations on sensitized and incompletely sensitized red blood cells (RBC) and the separation of agglomerates.

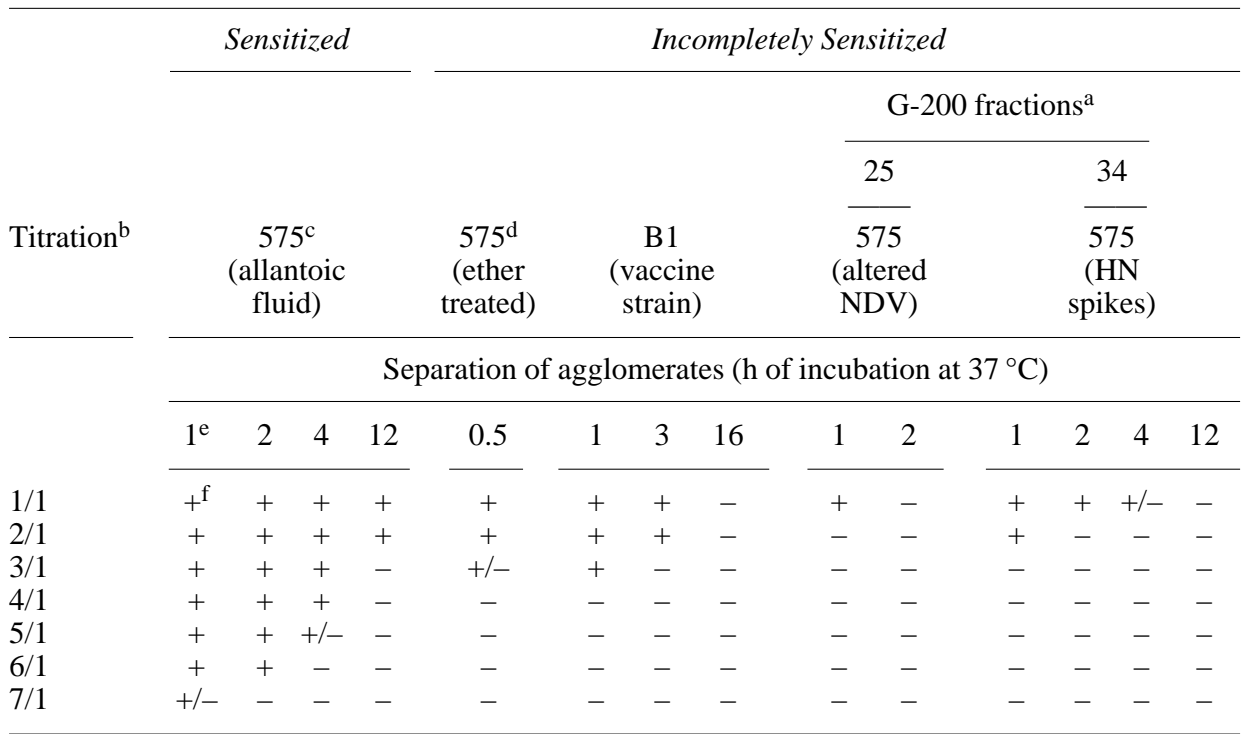

${ }^{\text {a }}$ The HN spikes in fraction 34 and altered NDV in fraction 25 were separated on sephadex as described in Figure 1.

${ }^{b}$ In the titration normal RBC were added to one volume of sensitized or incompletely sensitized RBC resulting in the proportions indicated.

${ }^{c}$ These results are essentially identical in tests with strain 575 in allantoic fluid which was chromatographed and located in fraction 25 .

${ }^{\mathrm{d}}$ See Table III for the serologic effects following ether treatment. HN spike preparations from ether-treated NDV were not incubated; other tests showed that the NA was functional and that the separation from normal RBC was rapid.

e The $0 \mathrm{~h}$ and $1 \mathrm{~h}$ recordings were equivalent.

${ }^{\mathrm{f}}$ The agglomerate of normal RBC and sensitized RBC remained agglutinated as designated by $(+)$, whereas separation or no agglutination is designated (-). Partial agglutination is designated (+/-).

Antibody reactions with ether-treated and control NDV: NDV in suspensions, completely and incompletely sensitized RBC, fluorescent antibody. The HN spikes removed from NDV in the AS reaction did not respond to anti-NA antibody (Tab. II). Tests were conducted with ether-treated NDV. Following elution of $\mathrm{HN}$ spikes, the incompletely sensitized RBC, although showing limited agglutination of normal RBC (Tab. I), failed to respond to SI antibody. Tests with suspensions of ether-treated NDV were positive for HI antibody, whereas the EI tests were negative. Fluorescent staining with discrete foci were on sensitized
RBC only if anti-NA antibody tests were positive (Tab. III).

\section{DISCUSSION}

Release of the AS products requires a reactivated NA and 2 reactions. Sensitized RBC are the only source of altered NDV, whereas the HN spikes have 2 sources: the NDV membrane and the sensitized RBC. The 2 known reactions were delineated by the concentrations of sialic acid as follows: AS reactions with limited sialic acid released 1.4 more altered NDV than HN spikes 
Table II. Antibody reactions with sensitized and incompletely sensitized red blood cells (RBC) and with suspensions of Newcastle disease virus (NDV).

\begin{tabular}{|c|c|c|c|c|}
\hline & $\begin{array}{l}\text { Altered NDV } \\
+ \text { HN spikes }\end{array}$ & $\begin{array}{l}\text { Altered NDV } \\
\text { Fraction } 25\end{array}$ & $\begin{array}{l}\text { HN spikes } \\
\text { Fraction } 34\end{array}$ & $\begin{array}{l}\text { Control NDV } \\
\text { Fraction } 25^{\mathrm{b}}\end{array}$ \\
\hline AI & 512 & 256 & 128 & 256 \\
\hline SI & $ـ^{c}$ & - & - & 2048 \\
\hline AS & $2 / 1^{\mathrm{d}}$ & $1 / 1$ & $2 / 1$ & $6 / 1+/-7 / 1$ \\
\hline
\end{tabular}

Separation of agglomerates (h of incubation at $37^{\circ} \mathrm{C}$ )

\begin{tabular}{lll}
$2^{\mathrm{e}}$ & & $2 / 1$ at $8 \mathrm{~h}$ \\
\hline
\end{tabular}

Reactions with suspensions of NDV (575 and B1)

\begin{tabular}{|c|c|c|c|}
\hline & $\begin{array}{c}\text { Altered NDV + } \\
\text { HN spikes }\end{array}$ & $\begin{array}{c}\text { B1 } \\
\text { Vaccine }\end{array}$ & $\begin{array}{l}\text { Control NDV } \\
\text { Fraction } 25^{\mathrm{b}}\end{array}$ \\
\hline & 64 & 40 & 40 \\
\hline EI & - & - & 256 \\
\hline
\end{tabular}

a Tests involving the neuraminidase: separation-inhibition (SI), elution-inhibition (EI); tests involving the haemagglutinin: agglutination-inhibition (AI), haemagglutination-inhibition (HI); test without antibody involving both the haemagglutinin and neuraminidase: agglutination-separation (AS). The tests used strains 575 and B1; the antiserum was from rabbit, 17 days post immunization.

${ }^{\mathrm{b}}$ Control NDV from allantoic fluid sensitized the RBC, whereas incomplete sensitization resulted from altered NDV and HN spikes (also see Table I). Not tabulated are replicate tests with control NDV in fraction 28, which gave similar results as with the NDV in fraction 25.

${ }^{c}$ Negative (-) test is when the agglomerates separate to the level of the AI titres.

$\mathrm{d}$ The ratios are normal RBC/incompletely sensitized RBC or normal RBC/ sensitized RBC. The agglomerates separated, thus the neuraminidase was functional although the SI and EI tests were positive only with control NDV in fractions 25 and 28. Incomplete sensitization with the B1 vaccine strain (see Table I) resulted in positive AI and HI tests and negative for SI and EI antibody.

e The AS test required $2 \mathrm{~h}$ for the $2 / 1$ titre to attain $1 / 1$ (see the titration on Table I for additional details).

$(8440 / 6060=1.4$; Fig. 1$)$. With sialic acid concentrations sufficient to reactivate the NA, altered NDV was predominantly released. The most probable source of the comparatively few HN spikes was the sensitized RBC surface, rather than the NDV membrane. In contrast, 5.4-fold more $\mathrm{HN}$ spikes were released in unlimited sialic acid reactions containing 3 normal to 1 sensitized RBC. And, following the limited AS reaction, this ratio was $3(1200 / 400=3$; Fig. 1). Thus more sialic acid was needed to extract the HN spikes from NDV.

Release of AS products is an orderly process governed by sialic acid concentrations. Binding and anchoring are mediated by hydrogen bonds and van der Waals contacts
$[27,52]$. The N-terminal sequence of the HN spike $[35,36]$ is anchored in the lipid bilayer aided by the $\mathrm{M}$ protein [14, 30, 34, 37, 39]. Interactions between HN spikes and M proteins [15] and perhaps lipids as well $[33,38]$ are disrupted during extraction. In contrast to insertion into NDV membranes [53], no apparent high-energy source is required for extraction. The mass of the normal RBC [44] may contribute to the physical forces needed to extract $\mathrm{HN}$ spikes from the NDV membrane. Except for fewer HN spikes on altered NDV, it is not known if other structural changes occur following the extraction [27].

Serologically, the AS products, the B1 strain and $\mathrm{HN}$ spikes from ether-treated 
Table III. The effects of ether treatment of Newcastle disease virus (NDV) assessed in serologic tests involving the haemagglutinin and neuraminidase.

\begin{tabular}{|c|c|c|c|c|c|c|}
\hline \multirow[b]{4}{*}{ Tests $^{\mathrm{a}}$} & & \multicolumn{5}{|c|}{ Immune sera } \\
\hline & \multicolumn{4}{|c|}{ Rabbit } & \multirow{2}{*}{\multicolumn{2}{|c|}{$\begin{array}{c}\text { Chicken } \\
\text { CDC }\end{array}$}} \\
\hline & \multicolumn{2}{|c|}{ \#33 } & \multicolumn{2}{|c|}{ \#98 } & & \\
\hline & Control & Ether & Control & Ether & Control & Ether \\
\hline & & & euramin & reactio & & \\
\hline SI & $1024^{\mathrm{b}}$ & $-^{\mathrm{c}}$ & $512^{\mathrm{d}}$ & - & 384 & - \\
\hline \multirow[t]{2}{*}{ EI } & 128 & $+/-16$ & 128 & - & 32 & - \\
\hline & \multicolumn{6}{|c|}{ Haemagglutinin reactions } \\
\hline AI & - & 192 & $+/-16$ & 192 & 24 & 256 \\
\hline \multirow[t]{2}{*}{$\mathrm{HI}$} & $+/-16$ & $+/-16$ & 16 & - & 16 & 16 \\
\hline & \multicolumn{6}{|c|}{ Undefined reactions } \\
\hline Agg P & - & - & - & - & - & - \\
\hline A & 192 & $+/-24$ & 192 & - & 48 & - \\
\hline
\end{tabular}

${ }^{\mathrm{a}}$ Tests were separation-inhibition (SI), elution-inhibition (EI); agglutination-inhibition (AI), and haemagglutinationinhibition (HI). Agglutination (Agg) tests may show pellet (P) formation and agglutination (A). The tests are included to show the initial reactions, which after the addition of normal red blood cells result in the AI and SI tests. ${ }^{\mathrm{b}}$ Reciprocal of the serum dilutions where end points were observed in the SI, AI, and Agg tests using RBC sensitized with strain 575. The EI and HI tests use a suspension of strain $575 \mathrm{NDV}$ containing $24 \mathrm{HA}$ units. If an end point did not occur at a specific dilution, the next higher dilution showing a partial (+/-), although permanent end point, was used to average the 2 end points in question.

${ }^{\mathrm{c}}$ Negative (-) tests at dilutions of $<1 / 16$.

${ }^{\mathrm{d}}$ The fluorescent antibody test for the presence of \#98 rabbit IgG on sensitized RBC was positive at serum dilutions of $1 / 128-1 / 512$, where the EI and SI reactions were positive, negative at $1 / 16$ and $+/-1 / 16$ where $\mathrm{HI}$ and $\mathrm{AI}$ tests were positive. Tests were also negative at dilutions of 1/1024-1/2048, where the concentrations of IgG were too low for staining. Sensitized RBC showed 1-8 discrete, small foci on most RBC indicating incomplete elution and aggregation of the NDV. In contrast, an evenly distributed "halo" was seen with ether-treated NDV indicating that $\mathrm{HN}$ spikes were on the RBC although no aggregation was seen (see [24]).

NDV respond only to anti-HA antibody, whereas sensitized RBC and strain 575 in supensions respond to anti-NA and anti-HA antibody. With correct configurations, more HA than NA antibody determinants, and an intact NDV, the SI and EI tests were positive and the titres exceed the AI and HI end points (Tabs. II, III) [22,24]. Associated with the SI reaction are fluorescent antibody foci on the RBC (Tab. III) [23]. Large aggregates of intact NDV on sensitized RBC may be another requirement for responding to anti-NA antibody. If foci are on incom- pletely sensitized RBC, the size is below the resolution limits of light microscopy, as would also be the case with suspensions of NDV.

In addition to the 3 known HA-sialic acid specificities [12, 28, 33], the inactive NA on sensitized $\mathrm{RBC}$ requires infrequent configurations and an intact NDV [26] with 1000 or so HN spikes [11]. The infrequency is apparent: Only 15-50 infectious and noninfectious NDV particles can bind to an avian RBC [6], and fewer are required to 
sensitize [4]. Electron micrographs of RBC show few NDV unless treated with $\mathrm{KIO}_{4}$ [6]. Further, the number of sialic acid-containing projections on a human $\mathrm{RBC}$ is 20 million; the number on chicken RBC is likely to be similar (personal communication, R. Schauer) [44]. Thus the average number of projections for each NDV approximates $400,000 \quad(20 \times$ $10^{6} / 50=400,000$ ), and for each HN spike the number is $400(400,000 / 1000=400)$; the total weight of the sialic acid is $18 \mu \mathrm{g}$ per $\mathrm{mL}$ of adult chicken RBC [28]. Regarding infectivity, one infectious unit requires 100 sensitized RBC [2]; hence infrequency is again apparent.

Partially purified HN spikes from sephadex fractions or those from ethertreated NDV do not completely elute from RBC. Thus the intact NDV is not a strict requirement for the configuration containing an inactive NA. Incompletely sensitized RBC agglutinated 1-3 volumes of normal RBC. The HA available for titration was less than the HA on sensitized RBC by factors of 6.5 to $3.2(6.5 / 1-3=6.5-3.2$; Tabs. I, II). Such differences are comparatively large; a 10\%-20\% reduction of sialic acid on a human RBC results in their removal from circulation [44].

Agglutination of sensitized RBC with fetuin titrates the $\mathrm{HN}$-sialic acid configuration. An average of the fetuin concentrations, where $50 \%$ and $100 \%$ agglutination was seen, is $0.023 \mathrm{mg}(0.018 \mathrm{mg}$ per $0.025 \mathrm{~mL}$ RBC; $0.21 \mathrm{mg} \times 8.7 \%=$ $0.018 \mathrm{mg}$; at $100 \%$ agglutination $0.027 \mathrm{mg}$, hence an average of $0.023 \mathrm{mg}$ ). Further, the equivalence with the sialic acid on normal RBC may also be indirectly estimated. Each volume of sensitized RBC agglutinates 6 to 7 volumes of normal RBC (Tabs. I, II)[26]; a mean value of 6.5 volumes approximates $50 \%$ agglutination. Accordingly, an equivalence of $0.0035 \mathrm{mg}$ sialic acid $(0.023 \mathrm{mg} / 6.5$ volumes $=0.0035 \mathrm{mg})$ is present on the surface of normal RBC in $0.025 \mathrm{~mL}$ of a $0.3 \%$ suspension.
Yields of NANA from fetuin were essentially the same with sensitized RBC in suspension or if agglutinated. With NDV suspensions EI antibodies completely inhibited the NA. Despite the NA inhibition, added fetuin was cleaved at $49-88 \%$ of maximum values [24]. Selective NA substrates are indicated in both systems. In the NA assay sensitized $\mathrm{RBC}$ reacting with sialic acid on normal RBC is up to 52-fold more efficient. Also, reactions with the sialic acid on RBC is more representational of a natural event than using artificial substrates $[1,26]$.

The B1 HN spike has a difference of 3 amino acid residues when compared with the sensitizing AV strain [46]. A cysteine residue was not found at position 123 [43]; thus the B1 HN spike, when removed from the NDV membrane, may be a monomer. And a cysteine-containing tetramer $\mathrm{HN}$ spike is required for $\mathrm{RBC}$ sensitization and for its responding to anti-NA antibody. Other differences were that the B1 strain failed in immunodiffusion tests as well as in sensitization of human RBC [40].

The B1 strain, released HN spikes, HN spikes from ether-treated 575 all eluted rapidly. All would be placed in the rapid elution group $[4,45]$. Others [18] have also described rapid elution of the HN spikes. The insertion of HN spikes into membranes could restrict the NA, resulting in slower elution. Complete sensitization as well as slow elution are dependent upon an intact NDV. The increase in HA titre with ether treatment and in the AS reactions could, in part, be due to tetramers of the $\mathrm{HN}$ spikes forming dimers [34, 35, 48]. The net result is higher than expected HA titres. Without ether treatment Anderson [2] measured increases in HA units up to 40-fold, provided that whole or lysed RBC were present in the titration. The AS products may have been responsible for the increase in HA titre.

The molecular mass of the $\mathrm{HN}$ spike indicates a dimer $[35,48]$. Conceivably the higher than expected value may be due to 
components of NDV not removed from the HN spikes, lipid for instance. The AS reactions are irreversible since the released $\mathrm{HN}$ spikes do not reinsert into the membrane of the altered NDV. Nor do the dimers of the $\mathrm{HN}$ spike form tetramers under the nonreducing conditions as was also found with cHN spikes [48]. Separation would not be possible (Fig. 1), hence irreversibility.

Conserved residues on the stalk of the $\mathrm{HN}$ spikes from the AV strain influence the NA but not the HA [51]. These residues may affect the configuration(s) necessary for anti-NA antibody inhibition without influencing the anti-HA assay (Tabs. II, III). In addition to having few anti-NA antibody determinants as proposed for strain 575 $[22,24]$, further examinations $[10,11,13$, $31,32]$ may find that certain NDV strains may have an HA and perhaps a second NA binding site; such is the case with the frequently isolated [23] avian influenza subtype 9 [50].

The AS reactions should account for the earlier, unexplained observations with sensitized RBC, such as extended HA titration end points, prozone reactions and the partial dissociation of HA activity and infectivity. Regarding dissociation [9] the filtrate may have contained HN spikes. Although not found here, HN spikes were in infected membranes and, to a lesser extent, in allantoic fluids [18]. Emulsifying the membranes or RBC in allantoic fluid would provide the necessary sialic acid to release AS products. To explain titre extension and prozones, Burnet [7] suggested that, rather than disaggregation of NDV as proposed by Anderson [2], the HA titre extension was due to "bridging" between RBC. However, no "fixed virus" on RBC was found [6]. Resuspension of the tests would provide sialic acid to initiate the AS reactions. Newly released AS products extend the end points as well as cause prozones; thus 2 characteristics of sensitizing strains. In contrast, essentially no titre extension, but only rapid elution and prozones occur with non-sensitizing strains, such as B1 [4] or the HN spikes [18]. These findings are consistent with the effects of the AS reactions and the fact that AS products and the $\mathrm{B} 1$ strain incompletely sensitize RBC (Tab. I).

Initiating the reactivation of the NA is a newly recognized function of sialic acid [ 33 , $36,41,44,49]$. Governing the composition of the AS products resulted from controlling the amount of sialic acid in the AS reactions (Fig. 1). Such governing is a ratelimiting event, which likely, is not a separate function of sialic acid.

Solution of the 3-dimensional HN structures $[11,48]$ of strains with and without sensitizing characteristics (Tabs. I, II) will provide insights into the molecular mechanisms for the inactive NA and its reactivation. Also the sequential effects of heat, the separation of the HA and NA activities [11, $22,48]$ in the AS, SI and EI reactions [24-26] and the sialic acid-HA configuration(s) which determine(s) complete and incomplete sensitization may also be resolved.

The HA-sialic acid binding specificities are present in many species and cell types (referenced in [25]). If the correct configurations are also present, an inactive NA should occur with cells other than RBC. Elution of NDV would cease providing time for $\mathrm{HN}$ and $\mathrm{F}$ glycoprotein interaction leading to cell-cell fusion and NDV penetration $[30,34,36]$.

\section{ACKNOWLEDGMENTS}

The technical assistance of Ms. A. M. Gresco is gratefully acknowledged. Supported by National Institutes of Health Grant AI13048.

\section{REFERENCES}

[1] Aminoff D., Methods for the quantitative estimation of $\mathrm{N}$-acetyl-neuraminic acid and their application to hydrolysates of sialomucoids, Biochem. J. 81 (1961) 384-392.

[2] Anderson S. G., The reaction between red cells and viruses of the influenza group: Studies with 
Newcastle disease, Aust. J. Exp. Biol. Med. Sci. 25 (1947) 163-174.

[3] Appleyard G., Oram J.D., The assay of influenza antineuraminidase activity by an elution inhibition technique, J. Gen. Virol. 34, (1977) 137-144.

[4] Bang F.B., Foard M. A., The effect of Newcastle disease virus on chicken red blood cells. I. Variation in agglutination patterns with different strains of virus, Am. J. Hyg. 55 (1952) 363-372.

[5] Bang F.B., Libert R., Agglutination of red cells altered by the action of Newcastle disease virus. I. The effect of chicken sera from infected birds on sensitized cells, Bull. Johns Hopkins Hosp. 85 (1949) 416-430.

[6] Bang F.B., Libert R., The effect of Newcastle disease virus on chicken red blood cells. II. A study of the adsorption, sensitization and elution process, Am. J. Hyg. 55 (1952) 363-385.

[7] Burnet F.M., The haemolytic action of Newcastle disease virus. I. The two types of interaction between virus and red cells, Aust. J. Exp. Biol. Med. Sci. 28 (1950) 299-309.

[8] Burnet F.M., Anderson, S.G., Modification of human red cells by virus action. II. Agglutination of modified human red cells by sera from cases of infectious mononucleosis, Brit. J. Exp. Pathol. 27 (1946) 236-244.

[9] Burnet F.M., Beveridge W.I.B., Mcewin J., Boake W. C., Studies on the Hirst haemagglutination reaction with influenza and Newcastle disease viruses. I. Partial dissociation of haemagglutinin and infective activity of Newcastle disease virus, Aust. J. Exp. Biol. Med. Sci. 23 (1945) 177-192.

[10] Colman P.M., Hoyne P.A., Lawrence M.C., Sequence and structure alignment of paramyxovirus hemagglutinin-neuraminidase with influenza virus neuraminidase, J. Virol. 67 (1993), 2972-2980.

[11] Crennell S., Takimoto T., Portner A., Taylor G., Crystal structure of the multifunctional paramyxovirus hemagglutinin-neuraminidase. Nat. Struct. Biol. 7 (2000) 1068-1074.

[12] Elliott M.A., Elliott H.G., McGuire J., Smith K.D., Regarding the specificity of Newcastle disease virus sialidase, Glycobiology 6 (1996) 5-12.

[13] Epa V.C., Modeling the paramyxovirus hemagglutinin-neuraminidase protein, Proteins Struct. Funct. Genet. 29 (1997) 264-281.

[14] Galinski M.S., Wechsler S.L., The molecular biology of the paramyxovirus genus, in: Kingsbury D. W. (Ed), The Paramyxoviruses, Plenum Press, New York, 1991, pp. 41-72.

[15] Garcia-Sastre A., Cabezas J.A., Villar E., Proteins of Newcastle disease virus envelope: interaction between the outer hemagglutinin-neuraminidase glycoprotein and the inner non-glycosylated matrix protein, Biochem. Biophys. Acta 999 (1989) 171-175.
[16] Gibbons R.A., Physio-chemical methods for the determination of the purity, molecular size and shape of glycoproteins, in: Gottschalk A. (Ed.), Glycoproteins. Their Composition, Structure and Function, Elsevier Publ. Comp., Amsterdam, 1972, pp. 31-140.

[17] Graham E.R.B., Fetuin, in: Gottschalk A. (Ed.), Glycoproteins. Their Composition, Structure and Function, Elsevier Publ. Comp., Amsterdam, 1972, pp. 717-729.

[18] Granoff A., Henle W., A small hemagglutinating component in preparations of Newcastle disease virus, J. Immunol. 72 (1954) 329-339.

[19] Graves I.L., Incorporation of radioactivity from ${ }^{14} \mathrm{C}$-sugars into macromolecule in polio-infected or guanidine-treated HeLa cells, J. Gen. Virol. 4 (1969) 101-109.

[20] Graves I.L., Utilization of radioactive carbon from glucose in biosynthesis of deoxyribonucleic acid, ribonucleic acid, polyglucose, and protein in vaccinia virus-infected HeLA cells, Am. J. Vet. Res. 30 (1969) 647-653.

[21] Graves I.L., Concerning the extraction, separation, and labeling with ${ }^{14} \mathrm{C}$-glucose of HeLa cell polyglucose, RNA and DNA and a comparison of the molecular weights and buoyant densities of polyglucose from poliovirus-infected and noninfected cultures, Biopolymers 9 (1970) 11-28.

[22] Graves I.L., Elution-inhibition antibody to Newcastle disease virus isolated from wild birds, Microbiology meetings, American Society of Microbiology, Washington, DC (abstract 5-196), May 4-9,1979, p. 272.

[23] Graves I.L., Influenza viruses in birds of the Atlantic flyway, Avian Dis. 36 (1992) 1-10.

[24] Graves I.L., The neuraminidase of Newcastle disease virus inhibited in the elution-inhibition reaction, Vet. Res. 27 (1996) 45-54.

[25] Graves I.L., Newcastle disease virus in birds of the Atlantic flyway: isolations, hemagglutinationinhibition and elution-inhibition antibody profiles, Vet. Res. 27 (1996) 209-218.

[26] Graves I.L., Heat inactivation of the neuraminidase and haemagglutinin estimated in the agglutination-separation reactions using red blood cells sensitized with Newcastle disease virus, Vet. Res. 30 (1999) 383-392.

[27] Haywood A.M., Virus receptors: binding, adhesion strengthening, and changes in viral structure, J. Virol. 68 (1994) 1-5.

[28] Herrier G., Reuter G., Rott R., Klenk H.D., Schauer, R., N-acetyl-9-O-acetylneuraminic acid, the receptor determinant for influenza $\mathrm{C}$ virus, is a differentiation marker on chicken erythrocytes, Biol. Chem. Hoppe- Seyler 368 (1987) 451-454.

[29] Karzon D.T., Bang F.B., The pathogenesis of infection with a virulent (CG 179) and an avirulent (B) strain of Newcastle disease virus in the chicken. I. Comparative rates of viral multiplication. II. Development of antibody. J. Exp. Med. 93 (1951) 267-296. 
[30] Lamb R.A., Kolakofsky D., The Paramyxoviruses, in: Field B.N., Knipe D.M., Howley P.M. (Eds.), Fundamental virology 3rd Ed., Lippincott Raven, Philadelphia, Pa. 1996, pp. 577-604.

[31] Langedijk J.P.M., Daus F.J., van Oirschot J.T., Sequence and structure alignment of paramyxoviridae attachment proteins and discovery of enzymatic activity for a morbillivirus hemagglutinin, J. Virol. 71 (1997) 6155-6167.

[32] Leeuw O., Peeters B., Complete nucleotide sequence of Newcastle disease virus: evidence for the existence of a new genus within the subfamily Paramyxovirinae, J. Gen. Virol. 80 (1999) 131-136.

[33] Markwell M. A.K., New frontiers opened by the exploration of host cell receptors, in: Kingsbury D.W. (Ed.), The Paramyxoviruses, Plenum Press, New York, 1991, pp. 407-422.

[34] McGinnes L.W., Sergel T., Morrison T.G., Mutations in the transmembrane domain of the HN protein of Newcastle disease virus affect the structure and activity of the protein, Virology 196 (1993) 101-110.

[35] Mirza A.M., Sheehan J.P., Hardy L.W., Glickman R.L., Iorio R.M., Structure and function of a membrane anchor-less form of the hemagglutinin-neuraminidase glycoprotein of Newcastle disease virus, J. Biol. Chem. 268 (1993) 21425-21431.

[36] Morrison T.G., Portner A., Structure, function, and intracellular processing of the glycoproteins of paramyxoviridae. in: Kingsbury D.W. (Ed.), The Paramyxoviruses, Plenum Press, New York, 1991, pp. 347-382.

[37] Munoz-Barroso I., Cobaleda C., Zhadan G., Shnyrov V., Villar E., Dynamic properties of Newcastle disease virus envelope and their relations with viral hemagglutinin-neuraminidase membrane glycoprotein, Biochem. Biophys. Acta 1327 (1997) 17-31.

[38] Neitchev V.Z., Dumanova L.P., Effects of the components of Newcastle disease virus on the structural order of lipid assemblies, Mol. Biol. Rep. 16 (1992) 27-31.

[39] Peeples M.E., Paramyxovirus M proteins: pulling it all together and taking it on the road, in: Kingsbury D. W. (Ed.) The Paramyxoviruses, Plenum Press, New York, 1991, pp. 427-456.

[40] Powell J.A., Kato K., Milgrom F., Antibodies to Newcastle disease virus in various human diseases, Int. Arch. Allergy Appl Immunol. 76 (1985) 331-335.

[41] Reuter G., Schauer R., Determination of sialic acids, in: Lennarz W., Hart G.W. (Eds.), Methods in Enzymology, Academic Press, San Diego, 230, 1994, pp. 168-199.

[42] Rott R., Antigenicity of Newcastle disease virus, in: Hanson R.P. (Ed.), Newcastle Disease Virus
An Evolving Pathogen, University of Wisconsin Press, Madison and Milwaukee 1964, pp. 133-146.

[43] Sakaguchi T., Toyoda T., Gotch B., Inocencio N.M., Kuma K., Nagai Y., Newcastle disease virus evolution: multiple lineages defined by sequence variability of the haemagglutinin-neuraminidase gene, Virology 169 (1989) 260-272.

[44] Schauer R., Sialic acids and their role as biological masks, Trends Biochem. Sci. 10 (1985) 357-360.

[45] Seal B., King D., Bennett J., Characterization of Newcastle disease virus vaccines by biological properties and sequence analysis of the hemagglutinin-neuraminidase protein gene, Vaccine 14 (1996) 761-766.

[46] Sheehan J.P., Iorio R.M., A single amino acid substitution in the hemagglutinin-neuraminidase of Newcastle disease virus results in a protein deficient in both functions, Virology 189 (1992) 778-781.

[47] Siebert H.C., Tajkhorshid E., von der Lieth C.W., Kleineidam S.K., Schauer R., Kaptein R., Gabius H.J., Vliegenthart J.F.G., Knowledge-based homology modeling and experimental determination of amino acid side chain accessibility by the laser photo CINDP (chemically induced dynamic nuclear polarization) approach in solution: Lessons from the small sialidase of Clostridium perfringens, J. Mol. Model. 2 (1996) 446-455.

[48] Takimoto T., Taylor G.L., Crennell S.J., Scroggs R.A., Portner A., Crystallization of Newcastle disease virus hemagglutinin-neuraminidase glycoprotein, Virology 270 (2000) 208-214.

[49] Traving C., Schauer R., Structure, function and metabolism of sialic acids, Cell Mol. Life Sci. 54 (1998) 1330-1340.

[50] Varghese J.N., Coleman P.M., van Donkelaar, A., Blick, T.J., Sahasrabudhe A., McKimmBreschkin J.L., Structural evidence for a second sialic acid binding site in avian influenza virus neuraminidases, Proc. Natl. Acad. Sci. USA, 94 (1997) 11808-11812.

[51] Wang Z., Iorio R.M., Amino acid substitutions in a conserved region in the stalk of the Newcastle disease virus HN glycoprotein spike impair its neuraminidase activity in the globular domain, J. Gen. Virol. 80 (1999) 749-753.

[52] Weiss R.A., Brown J.H., Cusack S., Paulson J.C, Skehel J.J., Wiley D.C., Structure of the influenza virus haemagglutinin complexed with its receptor, sialic acid, Nature (London) 333 (1988) 426-431.

[53] Wilson C., Gilmore R., Morrison T., Aberrant membrane insertion of a cytoplasmic tail deletion mutant of the hemagglutinin-neuraminidase glycoprotein of Newcastle disease virus, Mol. Cell. Biol. 10 (1990) 449-457. 